\title{
MÖNCH SETS AND FIXED POINT THEOREMS FOR MULTIMAPS IN LOCALLY CONVEX TOPOLOGICAL VECTOR SPACES
}

\author{
T. CARDINALI*, D. O'REGAN** AND P. RUBBIONI* \\ ${ }^{*}$ Department of Mathematics and Computer Sciences \\ University of Perugia, Perugia, ITALY \\ E-mail: tiziana.cardinali@unipg.it,paola.rubbioni@unipg.it \\ ** School of Mathematics, Statistics and Applied Mathematics, \\ National University of Ireland, Galway, Ireland \\ E-mail: donal.oregan@nuigalway.ie
}

Abstract. We present a variety of fixed point theorems for multimaps having weakly closed graph. We state in turn Sadovskii, Mönch and Daher type theorems which improve recent results in the literature. With this in mind, we introduce the definition of Mönch-set.

Key Words and Phrases: Mönch-set, condensing multimap, fixed point theorem, measure of noncompactness, weakly closed graph.

2010 Mathematics Subject Classification: 47H10, 47H08, $47 \mathrm{H} 04$.

Acknowledgements. The first and third authors have been supported by the Gruppo Nazionale per l'Analisi Matematica, la Probabilità e le loro Applicazioni (GNAMPA) of the Istituto Nazionale di Alta Matematica (INdAM) and by the National Research Project GNAMPA 2015 Metodi Topologici, sistemi dinamici e applicazioni.

\section{REFERENCES}

[1] R.P. Agarwal, D. O'Regan, Fixed-point theory for set valued mappings between topological vector spaces having sufficiently many linear functionals, Comput. Math. Appl., 41(2001), no. 7-8, 917-928.

[2] R.P. Agarwal, D. O'Regan, M.-A. Taoudi, Fixed point theorems for condensing multivalued mappings under weak topology features, Fixed Point Theory, 12(2011), no. 2, 247-254.

[3] T. Cardinali, F. Papalini, Fixed point theorems for multifunctions in topological vector spaces, J. Math. Anal. Appl., 186(1994), no. 3, 769-777.

[4] T. Cardinali, P. Rubbioni, Countably condensing multimaps and fixed points, Electron. J. Qual. Theory Differ. Equ., 83(2012), 1-9.

[5] T. Cardinali, P. Rubbioni, Multivalued fixed point theorems in terms of weak topology and measure of weak noncompactness, J. Math. Anal. Appl., 405(2013), no. 2, 409-415.

[6] Z. Denkowski, S. Migorski, N.S. Papageorgiou, An Introduction to Nonlinear Analysis: Theory, Kluwer Acad. Publ. Boston/ Dordrecht/ London, 2003. 
[7] M. Kamenskii, V.V. Obukhovskii, P. Zecca, Condensing Multivalued Maps and Semilinear Differential Inclusions in Banach Spaces, De Gruyter Ser. Nonlinear Anal. Appl. 7, Walter de Gruyter, Berlin - New York, 2001.

[8] G. Köthe, Topological Vector Spaces (I), Springer-Verlag, Berlin, Heidelberg, New York, 1969.

[9] D. O'Regan, R. Precup, Fixed point theorems for set-valued maps and existence principles for integral inclusions, J. Math. Anal. Appl., 245(2000), no. 2, 594-612.

Received: June 4, 2015; Accepted: December 4, 2015. 
